\title{
GLAD!
}

Revue sur le langage, le genre, les sexualités

$07 \mid 2019$

Varia

\section{Antoine Volodine. 2019. Frères Sorcières}

\section{La Joie Number Huit}

\section{(2) OpenEdition}

Journals

Édition électronique

URL : http://journals.openedition.org/glad/1766

DOI : $10.4000 /$ glad. 1766

ISSN : 2551-0819

\section{Éditeur}

Association GSL

\section{Référence électronique}

La Joie Number Huit, « Antoine Volodine. 2019. Frères Sorcières », GLAD! [En ligne], 07 | 2019, mis en ligne le 05 décembre 2019, consulté le 17 décembre 2020. URL : http://journals.openedition.org/glad/ 1766 ; DOI : https://doi.org/10.4000/glad.1766

Ce document a été généré automatiquement le 17 décembre 2020.

\section{(c) (i) (9)}

La revue GLAD! est mise à disposition selon les termes de la Licence Creative Commons Attribution Pas d'Utilisation Commerciale - Pas de Modification 4.0 International. 


\title{
Antoine Volodine. 2019. Frères Sorcières
}

\author{
La Joie Number Huit
}

\section{RÉFÉRENCE}

Antoine Volodine. 2019. Frères Sorcières. Paris : Le Seuil. 300 pages.

1 C'est la tradition, semble-t-il, des auteur.es post-exotiques que de commencer par une définition du post-exotisme. Je me rangerai donc à la tradition en commençant par là. Le post-exotisme rassemble 80 auteur.es, hommes et femmes emprisonné.es, une communauté de voix, un chœur de la prison, une littérature collective carcérale. Parmi elles et eux, émergent des voix singulières qui élaborent, selon des formes littéraires spécifiques, une mémoire et une histoire du désastre. C'est donc d'abord une littérature de l'oralité, qui se murmure sous les portes de prison. Frères sorcières fait partie de ces titres post-exotiques qui affirment à l'extérieur des murs les spécificités de cette littérature carcérale.

2 Le post-exotisme a toujours compté des femmes parmi ses auteur.es, des femmes qui parlaient. Mais voilà que, progressivement, depuis quelques livres, les femmes se mettent à parler de leur expérience. Et avec elles, apparaît donc la question des femmes. Et avec elle, apparaît donc la question de la violence. Herbes et Golem de Manuela Draeger affrontait directement la question du viol. De manière plus implicite, Terminus Radieux d'Antoine Volodine mettait en scène Hannko Vogoulian, Myriam Oumarik et Samiya Schmidt, en tant que filles, tant bien que mal - et plutôt mal - d'un chamane despotique. Frères sorcières reprend la question de plein fouet. Auto-déclaré cantopéra femelle, Frères sorcières traite de la fragilité et de la solidité de la solidarité entre femmes. 


\section{Si tu rencontres Myriam Dahaliane, il sera exactement malheur, zéro seconde !}

3 Quarante-troisième pièce de l'édifice post-exotique, Frères Sorcières est une entrevoûte en trois blocs. "Faire théâtre ou mourir », le premier texte, est un dialogue (sous forme d'interrogatoire ?) avec une actrice à propos de sa troupe de théâtre nomade, troupe qui tombe sur des bandits, bandits qui kidnappent les femmes de la troupe, et femmes qui deviennent alors femmes de bandits et bandites.

4 Le deuxième texte est un chœur de 7x7x7 vociférations, peut-être le plus beau passage, en tout cas le plus poétique. On ne sait pas très bien ce que c'est, c'est le texte d'une pièce de théâtre, d'une transmission, c'est un héritage, un texte magique, ou encore un répertoire de slogans pour les mauvais jours, etc.

5 "Dura Nox, Sed Nox », troisième texte, et le plus incongru, est le monologue en une assez longue et unique phrase de 120 pages d'un démiurge, « un immense sorcier mais aussi une immense sorcière sans que ça pose de problème ni éthique, ni organique de changer de sexe, de genre, jusque dans l'onomastie puisque le personnage porte des noms tels que Jean l'Insolente, Jeanne le Goudronneux, etc. », dit Volodine. Ce troisième bloc entraine un essoufflement physique, une temporalité carcérale qui ne s'arrête jamais.

6 À travers ces trois morceaux, se déploient les thèmes de l'entrevoûte. Volodine dit du livre qu'il parle de chamanisme, de magie et du refus de la violence faite aux femmes. Moi, il m'a parlé de théâtre, de viol, de genre et de désastre.

\section{Si toutes en ta présence murmurent que tu es déjà morte, ne t'alarme pas !}

7 Le viol est omniprésent, des bandits violent des actrices, des colosses violent des monstresses, des hommes violent des femmes. De manière incessante, sexe et sexualités sont des armes: armes de viol, armes de manipulation, armes de pénétration (dans les différents sens du terme, ici), armes d'aliénation, armes de salissement, armes d'amollissement. Et on comprend rapidement que c'est la violence du viol qui rend femmes. Se solidariser, convoquer et transmettre des mémoires de femmes, répondre, maudire, tuer, se transformer sont alors des réponses au viol et des échappées à la condition de femelle.

8 Le viol est abordé ici de manière bien plus brute et plus brutale que chez Manuela Draeger, peut-être parce que c'est un texte écrit par un homme? On y voit d'ailleurs la démultiplication du masculin, et en même temps la toute-puissance dénudée par son ridicule, un déplacement du masculin vers le surhumain, fait de surplus de savoir, de pouvoir et de mémoire, que la soif de pouvoir et de domination rend monstrueux. C'est finalement peut-être un texte sur les hommes, encore plus que sur les femmes.

De manière implicite mais omniprésente, le genre, sa violence et la réponse à cette violence se négocient aussi en termes de générations. La lignée Schubert se transmettant de grand-mères en petites filles des vociférations guérissantes, les mille et une vies incessantes, et ce démiurge qui encore et toujours, au-delà du temps, se génère, se régénère, (se) reproduit, renait, et constitue in fine ce qui reste. 
Quoi qu'il en soit, à travers le continuum de la phrase du dernier texte, on voit le féminin et le masculin devenir le nom de l'équivoque de la domination. Et c'est en fait tout un déplacement du politique vers la domination qui s'opère dans le livre, comme si le politique était ramené à ses fondamentaux: l'empêchement, l'entravement, la coercition.

11 Il y a aussi, bien sûr, la prouesse formelle propre au post-exotisme, la frime de la maitrise de l'invisible du langage, la minutie de l'édification ternaire des textes dans les effets de symétrie, et de résonnances mathématiques, un essaim de lettres et de chiffres invoquant la fonction magique du langage, pour «projeter lecteur et lectrice dans un monde différent de leurs références réalistes, mais les projeter de manière assez intense dans ce monde pour toucher à l'inconscient collectif, provoquer un décalage mais qui soit très familier » (Volodine, dans une présentation, le 31 octobre 2019).

\section{Moi, Jean Ostalnoï, je ne vois plus de toi qu'une chienne magique alliée à un chien de flammes, et j'apprécie tellement peu ta compagnie que je quitte cette plage empuantie par ton odeur de pourriture}

C'est la combinaison, le tissage qui produisent cette projection. Il y a bien un peu de néologisme qui traine dans le sillage des bandites, mais il demeure en hapax, et la violence arrive plutôt par le martellement incessant et la profusion des situations qui s'écrasent les unes les autres, comme dans des bruits assourdissants de frappe métallique, et dont l'exemple le plus percutant est peut-être cette langue qui n'a qu'un seul mot pour «femme » et " viande ». Le propos est si violent qu'on le détourne par le rire, et pourtant, l'anarchiste féministe chinoise He-Yin Zhen écrivait, sans nous faire rire le moins du monde, que «la femme est le nom du rang le moins respecté. Il ne s'agit que de vente et d'achat de chair » (1907).

13 Reste ce titre, Frères sorcières qui, à l'issue de la lecture, nous interroge peut-être plus par son pluriel que par cet apparent oxymore de genre, qui est en fait résolu par la toute-puissance de ce personnage qui commence par être Hadeff Kakaïne. Frères sorcières, aussi, peut-être comme une sortie offerte aux actrices qui pour se sauver n'ont guère d'autre choix que de s'échapper de ce qui les fait femmes et de devenir solidaires.

elle eut la curiosité de s'informer auprès de lui au sujet des deux mastodontes qui l'avaient violée, décrivant sommairement leur ossature monstrueuse, leur cachesexe qui ne cachait rien, l'air idiot de l'un et l'air dément de l'autre, et son interlocuteur hocha du chef et sortit un tranchoir d'une poche de son pardessus et il dit, ou plutôt il bougonna en allant vers elle comme vers une brebis d'abattoir, "Je les connais, ce sont mes frères, ils m'avaient prévenu que leur viande allait passer ", et, plus que le tranchoir ou le refus d'ouvrir la vanne, ces paroles révoltèrent Amandine Odilone à un point tel que, sans le toucher, elle infligea à l'homme une douleur térébrante, réglant celle-ci pour qu'elle le fasse souffrir et l'aveugle jusqu'à sa mort ou ce qui en tiendrait lieu, puis, comme l'homme subitement privé de vue gesticulait en hurlant et tranchait l'ombre avec une frénésie si désordonnée qu'il menaçait de s'automutiler, elle lui cassa les clavicules puis lui arracha les bras au niveau des coudes, et, le laissant ensuite s'agiter et vociférer vainement dans le noir, elle se pencha au-dessus de la borne et débloqua la vanne, or c'est à peine si un filet d'eau s'échappa de la canalisation, et elle songea que l'homme avait prévu de la tromper, exigeant d'elle d'infectes succions et 
pénétrations en échange de quelques gouttes, et comme l'eau ne venait pas, elle alla explorer la masure de l'homme et elle n'y débusqua rien d'autre qu'un seau de pisse à moitié plein qu'elle alla lui vider dessus, ainsi aggravant son humiliation et les sensations de brûlure sur ses plaies

\section{BIBLIOGRAPHIE}

DRAEGER, Manuela. 2012. Herbes et Golem. Paris : L'Olivier

VOLODINE, Antoine. 2014. Terminus Radieux. Paris : Le Seuil

\section{INDEX}

Thèmes : Actualités

Mots-clés : littérature, post-exotisme, femmes, viol, désastre

Keywords : literature, post-exotism, women, rape, disaster

\section{AUTEURS}

\section{LA JOIE NUMBER HUIT}

La Joie Number Huit aime bien la littérature post-exotique, avec laquelle elle partage une forte appréciation du sentiment de désastre. Elle écrit quelques textes, en lit beaucoup d'autres, compile des bestiaires, des valises vides et des lettres mortes. 